\title{
Using Collaborative Strategic Reading with Refugee English Language Learners in an Academic Bridging Program
}

Refugee students arrive in Canada with varying amounts of previous formal education. School-aged refugees who lack a solid first language education may find learning to read in English and studying subject content especially challenging. If these students leave school, they depart with inadequate English reading proficiency for further academics or job training. Reading strategy instruction could potentially contribute to improving their reading comprehension. In this article, I outline the implementation of Collaborative Strategic Reading in an academic bridging program for low-literate refugee students 17 to 25 years old, followed by some of the observed accompanying benefits. Descriptions and examples of activities used are included, along with references for additional teaching resources.

Les étudiants réfugiés arrivent au Canada avec des niveaux de scolarité formelle variables. Les réfugiés en âge d'être scolarisés qui n'ont pas une bonne base scolaire dans leur première langue risquent d'avoir du mal à apprendre la lecture et les matières académiques en anglais. Si ces élèves quittent l'école, ils partent sans la compétence en lecture de l'anglais nécessaire pour poursuivre leur scolarité ou une formation professionnelle. L'enseignement de stratégies de lecture pourrait contribuer à l'amélioration de leur compréhension en lecture. Dans cet article, je retrace la mise en œuvre d'un programme de lecture stratégique collaborative dans un programme de transition académique auprès d'élèves réfugiés peu alphabétisés et âgés entre 17 et 25 ans, et j'évoque quelques uns des bienfaits qui en découlent. Des descriptions et des exemples d'activités sont fournis, ainsi que des références indiquant des ressources pédagogiques supplémentaires.

KEYWORDS: reading instruction, refugees, English language learners, reading strategies, literacy

Between 2004 and 2014, approximately 300,000 refugees resettled in Canada (Immigration, Refugees and Citizenship Canada, 2016). Unlike other immigrant populations, refugees flee their home countries to escape from turmoil without the option of returning. For those who successfully find sanctuary in other countries, their one-way journey often involves an abrupt transition. Children may experience separation from their families and friends, as well as interruptions in their schooling. Prior to resettlement in Canada, many of these children reside in refugee camps; although their immediate safety may have been secured, their situations remain perilous in camps. For example, 
childhood malnourishment has been documented in a number of camps in Africa and Asia (Lutfy, Cookson, Talley, \& Rochat, 2014). Likewise, universal education remains far from a reality. According to the United Nations High Commissioner for Refugees (2016), less than half of school-aged refugees (total of approximately 10 million) under their care have access to primary $(50 \%)$, secondary $(25 \%)$, or postsecondary schooling $(1 \%)$. Therefore, within the refugee population, variability in premigration experiences including the quantity and quality of education exists. The focus of the present article is on refugees who have limited first language education or encountered interruptions in their formal schooling prior to arrival in Canada. This group of students has been referred to in the literature with names and acronyms such as learners with interrupted education (LIFE) (Bow Valley College, 2009) or students with interrupted formal education (SIFE) (e.g., Menken, 2013). Research on LIFE/SIFE commonly examines the relationship between language and literacy proficiency and academic achievement, with the participant population often composed of refugees (e.g., Kanu, 2008). Rossiter and Derwing (2012) highlighted the challenge of providing quality English as a second/ additional language programming for this historically marginalized group of students who are at increased risk of dropping out of the K-12 school system. Sadly, Rossiter and Derwing were able to identify Canadian policies that further contribute to interrupted schooling for immigrant and refugee students.

In Alberta at one point, students who left the K-12 system were required to be out of school for a minimum of one year prior to being eligible for financial assistance for additional schooling. This posed a systematic barrier for economically disadvantaged students. In response, one of my colleagues spearheaded an initiative that resulted in a fully funded academic upgrading program at a local community college for immigrant and refugee students with limited formal education whose English reading and writing abilities were below age-equivalent grade levels. Currently in its 10th year, the program's raison d'être is to improve reading comprehension ability, writing proficiency, mathematical knowledge, and general school readiness of English language learners (ELL) between the ages of 17 and 25 so that they meet the prerequisites of high-school level education and beyond. In essence, it serves as an academic bridging program. I have worked as an instructor in the program (hereafter pseudonymously referred to as youth transition program, or YTP); the purpose of the present article is to describe the implementation of a reading strategy instruction approach, Collaborative Strategic Reading, that has been positively received by the students in YTP.

\section{Rationale and Theoretical Foundations}

\section{Reading Comprehension and Learning}

For monolingual English-speaking students, Grade 4 generally marks the transition from learning to read to reading to learn (Chall, 1996). Arguably, 
learning to read continues throughout one's education career as the student encounters various styles of writing found in different academic subjects. Unfortunately, for refugee students who have experienced interruptions in (or lack of) formal schooling, their reading skills in any language have yet to be sufficiently developed prior to entering the Canadian school system. Upon entrance into Canadian schools, these students face the monumental task of simultaneously improving their general English language ability and English reading comprehension proficiency, and acquiring content knowledge in different subject areas. Toohey and Derwing (2008) have found that some high-school-aged ELLs avoid language-heavy courses that are typically accompanied by discipline-related readings. However, subjects that involve relatively large amounts of reading (e.g., English, social studies, biology) often serve as prerequisites to further education, and avoidance effectively brings ELLs' academic pathway to an end.

\section{Model of Second Language Reading}

Only one general descriptive model of reading in a second language (L2) reading exists to date. Informed by interactive models of reading such as Stanovich (1980), Bernhardt $(2005,2011)$ attempted to elucidate the relationship between first language (L1) and L2 reading skills. The result is a compensatory model of second language reading. It encapsulates variables that include L1 literacy (i.e., phonemics, text structure, purposes for reading, sentence configuration), L2 language knowledge (e.g., grammatical form, vocabulary knowledge, cognates), and a concept called unexplained variance that accounts for how readers interact with the text (e.g., comprehension strategies). In this model, one source of knowledge compensates for deficiencies in others. Bernhardt (2005) noted that previous studies in L2 reading (Bernhardt \& Kamil, 1995; Bossers, 1991; Brisbois, 1995; Carrell, 1991) estimated that L1 reading ability and L2 knowledge predicted $14-21 \%$ and 30\% of L2 reading performance, respectively. Accordingly, in her model, Bernhardt postulated L1 literacy to account for $20 \%$ of the performance variance in L2 reading, L2 language knowledge for $30 \%$, and unexplained variance for $50 \%$. The three knowledge sources "operate synchronically, interactively, and synergistically" (Bernhardt, 2005, p. 140). For refugee students without a solid L1 reading foundation and with weak L2 knowledge, use of comprehension strategies potentially makes a positive impact. Ironically, reading strategies are often developed in formal education contexts, which many refugees lack, where students are required to read. Therefore, explicit reading strategy instruction could address that gap.

\section{Strategy Instruction}

In this article, I adapt Afflerbach, Pearson, and Paris's (2008) conceptualization of reading strategy and skill: 
Reading strategies are deliberate, goal-directed attempts to control and modify the reader's efforts to decode text, understand words, and construct meanings of text. Reading skills are automatic actions that result in decoding and comprehension with speed, efficiency, and fluency and usually occur without awareness of the components or control involved. (p. 368)

Based on the definitions above, aiming for the development of skillful readers who can execute strategies effortlessly serves a meaningful pedagogical goal. In doing so, not only would teachers help refugee ELLs cope with challenging school reading requirements, but it may help students become autonomous learners capable of utilizing texts as an additional independent study resource.

\section{Collaborative Strategic Reading}

Collaborative Strategic Reading (CSR) is an approach to reading comprehension strategy instruction combined with cooperative learning: teachers provide students with the metacognitive knowledge of reading strategies through explicit instruction. From a Vygotskyian sociocultural perspective, interaction between students in mixed-ability grouping promotes a learning environment situated in the zone of proximal development (Vygotsky, 1986): through working together, students arrive at comprehension of a text that they could not previously understand individually. Teachers explicitly instruct students on specific reading strategies including previewing, monitoring comprehension, finding the main ideas, summarizing, and questioning. Later on, the students adopt expert roles on each of the strategies and work in small groups to comprehend a given text. Studies on CSR that included language-minority learners have demonstrated performance improvements on standardized reading exams (Boardman, Klingner, Buckley, Annamma, \& Lasser, 2015; Klingner, Vaughn, Arguelles, Hughes, \& Ahwee Leftwich, 2004; Klingner, Vaughn, \& Schumm, 1998; Vaughn et al., 2011). As well, research on CSR outside of the language arts classroom showed promise: not only does consistent integration of CSR into science and social studies classes lead to improved reading comprehension as measured by a standardized reading test (the widely used Gates-MacGinitie Reading Test), but teachers in these content classes also provided students with substantially more reading activities (compared with traditional social and science classes) along with increased attention "to the quality of student work and providing feedback to students when using CSR" (Boardman et al., 2015, p. 1278). The rest of the present article includes a description on how CSR has been implemented in YTP.

\section{Learning Context and Learner Characteristics}

At its inception, YTP catered to immigrant and refugee youth who recently exited the K-12 system but still lacked high-school-level reading proficiency. Some have even mistakenly thought they graduated from Canadian high 
schools, understandably - they were enrolled full-time and attended the graduation ceremony with their peers. Unfortunately, none possessed sufficient credential or foundational reading ability to continue schooling. Compounding the problem, they found themselves in a "no-man's land" where they were ineligible for additional publicly funded education (because of age caps) or provincial funding (they needed to wait at least one year after leaving school) that would alleviate the prohibitive costs associated with schooling. YTP offered a solution. Offered by a community college, YTP was designed for 17-to-25-year-old ELLs with less than 10 years of formal education, English reading ability assessed at grade-equivalent of 8 or below, and English speaking and listening ability above Canadian Language Benchmarks 4 (Centre for Canadian Language Benchmarks, 2012). The composition of the student population varies from year to year, but the majority has predominantly been refugees; countries of origin often changed along with the global climate (i.e., war or natural disasters). The gender ratio has normally been three females to two males. Class sizes have also fluctuated from 10 to 20 students (a maximum cap). New intake to the program may occur every two months. Some students exit when their reading proficiency reaches the next academic program's prerequisite level while others may leave for personal reasons. Currently, the program continues to run full-time from September to June with three different classes grouped according to similar reading proficiency levels. Therefore, any given class contains a heterogeneous cohort.

All of the instructors in YTP are required to hold an Alberta teaching certificate (which requires a Bachelor of Education degree). The instructors have had a high degree of autonomy in designing and changing the program curriculum and instruction delivery. However, all levels of classes in YTP share the same program design: content is taught in two-months-long thematic units; concerning reading, students in each level receive one to one-and-a-half hours of reading class each day for four days a week; and readings comprise literature and expository texts depending on the unit of study. In the eighth week, a reading comprehension test designed by the teacher using a text similar in genre, organization, and difficulty to ones that students have encountered throughout the unit is administered.

CSR in YTP as outlined below had been delivered over the past three academic years by one of the instructors who studied it as part of a Master of Education program. The class in which this instructor taught was the highest level in the program, with reading levels typically ranging from as low as Grade 5 to Grade 8 (at which point they meet the requirements to enter other programs at the college, such as mainstream upgrading courses or a trade apprenticeship preparation program).

\section{Instructional Procedure}

The following description is meant to demonstrate how CSR has been carried out in YTP. Teachers who are interested in using CSR are encouraged to 
also consult Klingner, Vaughn, Boardman, and Swanson (2012) for additional details and reproducible worksheets.

CSR is divided into three stages: before reading, during reading, and after reading. The before reading stage involves a preview of the text. During reading, comprehension monitoring of vocabulary or content is achieved through a strategy called click and clunk. Repairing breakdowns in comprehension is also carried out at this stage, followed by getting the gist, which requires finding main ideas in each section of a text. After reading, wrap-up is conducted by having students create questions accompanied by answers (as if they were the teacher) as well as a summary of the text. Once students are able to execute the strategies, they engage in small group reading and play one of four roles: leader, clunk expert, gist expert, and question expert. Students in YTP are introduced to CSR early in the school year in September. An overview of the sequence of instruction is as follows:

Step 1: Explicit instruction of strategies

Step 2: Whole class reading with teacher modelling

Step 3: Whole class reading with students as leader and experts

Step 4: First separate group reading

Step 5: Second separate group reading

Step 6: Whole class reading-similar to Step 3

Step 7: Last separate group reading

\section{Step 1: Explicit Instruction of Strategies}

Explicit instruction on how to utilize the reading strategies outlined in CSR is delivered over six lessons. Note that there is no one-to-one relationship between lesson and days. A lesson may span several classes, or some days may include two lessons. When working with our students, we have found that allowing for variability and flexibility in schedule is necessary to accommodate students working at different speeds.

In the first two lessons, students are introduced to the concept of clicks and clunks along with four strategies to overcome clunks. As students read, they are encouraged to monitor their comprehension; clicks refer to words or concepts in the text that students understand, whereas a clunk is encountered when students arrive at an incomprehensible word or idea. The four repair strategies presented to students are as follows: (a) reread the sentence with the clunk and look for clues (e.g., appositives) to figure out unknown vocabulary; (b) reread the sentences before and after the clunk for other contextual clues; (c) look for affixes and root words in the clunk for clues; (d) determine parts of speech to aid understanding or look for similar words in your first language (cognates). For follow-up practice, the teacher provides students with a worksheet containing sentences and short passages with predeter- 
mined clunks (underlined words). Students are required to find the meaning of the clunk by utilizing one of the four strategies and explicitly state which repair strategy was used. An example practice question might resemble the following:

When you find a clunk, or a word you don't understand, stop and try to figure it out.

Clunk = [student provides the definition]

Which strategy did you use? $\quad \begin{array}{lllll}1 & 2 & 3 & 4\end{array}$

In Lesson 3, students learn how to get the gist or finding the main idea of a section in a reading. Strategies presented to students are in the form of two questions and a statement: (a) "Who" or "what" is the most important in this section? (b) What is the most important information about the "who" or "what"? (c) Write a short sentence about the "who" or "what" by combining answer from (a) and (b). Again, the teacher prepares a worksheet with a passage for practice that also recycles identifying and repairing clunks.

Lessons 4, 5, and 6 involve students learning to write three different types of questions and answers - the after reading wrap-up stage. The first type of question is right-there questions, or questions that can be answered with information found directly in the text. The second type is think-and-search questions that require looking in two different places in the text (e.g., compare and contrast). The third is author-and-you questions, answers to which combine information directly from the text and the readers' background knowledge. Separate worksheets are given to students to practice questions-and-answers creation, as well as revisiting the other strategies learned in Lessons 1 through 3 . A cheat sheet with a variety of generic question stems for each of the question types prepared in advanced by the instructor for the students has been especially helpful (e.g., What is the same? Why do you think ? How are and

\section{Step 2: Whole Class Reading with Teacher Modelling}

Once students are able to perform each of the strategies above, the class read a text together. Before reading, the teacher hands out a CSR learning log (see Klingner et al., 2012, p. 142, for a ready-made example) that includes spaces for students to record their findings from the preview, clunks (limited to three) and definitions along with strategy used, the gist of each section, three types of questions, and a review section to summarize the text. At this point, the teacher models how to preview a text via think aloud - focus on the title, subtitles, keywords; activate prior knowledge; make predictions. Students write down the teacher's thoughts in their CSR learning log. As the class reads together, the teacher plays the roles of the clunk expert, gist expert, and question expert, demonstrating to the students how to apply the strategies taught in Step 1. The teacher also helps the students with filling out their logs. This step usually takes a week to complete for the YTP class. 


\section{Step 3: Whole Class Reading with Students as Leader and Experts}

Using another text, the teacher begins by leading the preview, but scaffolding is gradually reduced by assigning four students to the roles of leader and experts. To facilitate the transition, the instructor prepares a CSR script (Appendix) outlining, in order, what every person has to say or do. This script deviates from the cue cards used by Klingner et al. (2012); the YTP instructor found that when students in each role were given a separate cue card with their respective job descriptions, knowing "whose turn it was to do what" was challenging for the students as a group. A two-page script helped students to see and reinforce the overall CSR process. Again, as the student leader and experts play their roles, the rest of the class complete their CSR logs. This step also typically takes a week.

\section{Step 4: Separate Group Readings}

By now, students should be familiar with the CSR process. The teacher creates groups of four students with mixed abilities. These groups remain together for the duration of the unit. The teacher gives the groups three different texts (the number of texts may have to be adjusted based on the class size) to choose as their reading assignment. Prior to choosing, the teacher leads the preview one last time for all three texts, after which the groups choose a reading that interests them the most. A reading may be assigned to more than one group. Once all the readings have been assigned, groups read together, following the CSR script. Students are responsible for completing their own CSR logs.

Once all of the groups have finished, each presents a group summary of the reading to the entire class. Teacher may wish to use this activity as a listening task for the other students.

\section{Steps 5, 6, and 7}

For the remainder of the unit, students practice CSR with three more readings. In the same groups, members play a different expert role for different readings. The teacher circulates through the classroom, monitoring and providing assistance as necessary. CSR logs are collected and marked.

\section{Discussion and Conclusion}

Since the implementation of CSR in YTP, instructors have observed qualitative differences in students' reading strategy use. Prior to learning about CSR, some students did monitor their comprehension and "stop and try to understand" when faced with unknown vocabulary or ideas; however, presumably because of their less robust formal education backgrounds, they lacked the knowledge of how to compensate for breakdowns in reading comprehension. In subsequent months, instructors noticed the students actively engaging with novel texts by using the strategies learned during the CSR unit without prompting from the teacher. Perhaps students internalized the 
strategies through repetitive practice during CSR training - a plausible reality if we consider strategy use and reading in general to be a skill. According to skill acquisition theory, learning a skill begins with explicit instruction, and control and execution becomes increasingly efficient or even automatic with practice (Anderson, 1993, 2007). While the YTP instructor delivering CSR instruction consciously selected only expository readings that shared common organizational structures, the instruction appears impressively to have led to transfer appropriate processing (DeKeyser, 2007) in that students applied the CSR strategies to literary readings in later units, again without further explicit instruction from the instructor. More importantly, students have stated that they enjoy the opportunity for group work and find the CSR process helps them understand challenging texts.

For the YTP cohorts taught with CSR, improvements of students' results from standardized reading exams (Test of Basic Adult Education, or TABE) of at least one grade level have been recorded between test administrations (September, December, and April). Unfortunately, definitive statements on the quantitative improvements in reading and overall school performance owing to CSR cannot be made here due to the lack of any experiments conducted with YTP students; however, as noted above, previous research of CSR hints at its potential. At the very least, no detrimental effects on academic performance have been observed. It stands to reason that CSR would benefit refugee students by increasing their awareness and use of reading strategies, thereby potentially improving their reading comprehension, and providing them with oral interaction opportunities for additional English language practice in an academic setting.

\section{Acknowledgements}

I would like to thank my colleagues in the program mentioned in this article, particularly the team lead who implemented CSR and shared her knowledge with me. I am grateful to the anonymous reviewers for their encouraging and valuable feedback. Finally, thank you to former students who are my motivation for writing.

\section{The Author}

Kent Lee is a Ph.D. candidate in the Teaching English as a Second Language (TESL) program in the Department of Educational Psychology at the University of Alberta, Canada. His research interests include second language reading and teacher education.

\section{References}

Afflerbach, P., Pearson, P. D., \& Paris, S. G. (2008). Clarifying differences between reading skills and reading strategies. Reading Teacher, 61(5), 364-373. https://doi.org/10.1598/RT.61.5.1

Anderson, J. R. (1993). Problem solving and learning. American Psychologist, 48(1), 35-44. https:// doi.org/10.1037/0003-066X.48.1.35

Anderson, J. R. (2007). How can the human mind occur in the physical universe? New York, NY: Oxford University Press.

Bernhardt, E. B. (2005). Progress and procrastination in second-language reading. Annual Review of Applied Linguistics, 25, 133-150. https://doi.org/10.1017/S0267190505000073

Bernhardt, E. B. (2011). Understanding advanced second-language reading. New York, NY: Routledge. 
Bernhardt, E. B., \& Kamil, M. L. (1995). Interpreting relationships between L1 and L2 reading: Consolidating the linguistic threshold and the linguistic interdependence hypotheses. Applied Linguistics, 16(1), 15-34. https://doi.org/10.1093/applin/16.1.15

Boardman, A. G., Klingner, J. K., Buckley, P., Annamma, S., \& Lasser, C. J. (2015). The efficacy of Collaborative Strategic Reading in middle school science and social studies classes. Reading and Writing, 28(9), 1257-1283. https://doi.org/10.1007/s11145-015-9570-3

Bossers, B. (1991). On thresholds, ceiling, and short circuits: The relation between L1 reading, L2 reading, and L2 knowledge. AILA Review, 8(1), 45-60. Retrieved from http://www.aila.info/ download/publications/review/AILA08.pdf

Bow Valley College. (2009). Learning for LIFE: An ESL literacy handbook. Calgary, AB: Author. https://centre.bowvalleycollege.ca/tools/learning-life-esl-literacy-handbook

Brisbois, J. E. (1995). Connections between first- and second-language reading. Journal of Reading Behavior, 27(4), 565-584. https://doi.org/10.1080/10862969509547899

Carrell, P. (1991). Second language reading: Reading ability or language proficiency? Applied Linguistics, 12(2), 159-179. https://doi.org/10.1093/applin/12.2.159

Centre for Canadian Language Benchmarks. (2012). Canadian Language Benchmarks: English as a second language for adults. Ottawa, ON: Author. http://www.cic.gc.ca/english/pdf/pub/language-benchmarks.pdf

Chall, J. S. (1996). Stages of reading development (2nd ed.). Fort Worth, TX: Harcourt-Brace.

DeKeyser, R. M. (2007). The future of practice. In R. M. DeKeyser (Ed.), Practice in a second language: Perspectives from applied linguistics and cognitive psychology (pp. 287-304). New York, NY: Cambridge University Press.

Immigration, Refugees and Citizenship Canada. (2016). Facts and figures 2014-Immigration overview: Permanent residents. Retrieved from http://www.cic.gc.ca/english/resources/statistics/ facts2014/permanent/01.asp

Kanu, Y. (2008). Educational needs and barriers for African refugee students in Manitoba. Canadian Journal of Education, 31(4), 915-940. Retrieved from http://files.eric.ed.gov/fulltext/ EJ830509.pdf

Klingner, J. K., Vaughn, S., Arguelles, M. E., Hughes, M. T., \& Ahwee Leftwich, S. (2004). Collaborative strategic reading: "Real-world" lessons from classroom teachers. Remedial and Special Education, 25(5), 291-302. https://doi.org/10.1177/07419325040250050301

Klingner, J., Vaughn, S., Boardman, A., \& Swanson, E. (2012). Now we get it! Boosting comprehension with collaborative strategic reading. San Francisco, CA: Jossey-Bass.

Klingner, J. K., Vaughn, S., \& Schumm, J. S. (1998). Collaborative strategic reading during social studies in heterogeneous fourth-grade classrooms. Elementary School Journal, 99(1), 3-22. https://doi.org/10.1086/461914 Retrieved from http://www.jstor.org.login.ezproxy.library. ualberta.ca/stable/1002223

Lufty, C., Cookson, S. T., Talley, L., \& Rochat, R. (2014). Malnourished children in refugee camps and lack of connection with services after US resettlement. Journal of Immigrant and Minority Health, 16(5), 1016-1022. https://doi.org/10.1007/s10903-013-9796-6

Menken, K. (2013). Emergent bilingual students in secondary school: Along the academic language and literacy continuum. Language Teaching, 46(4), 438-476. https://doi.org/10.1017/ S0261444813000281

Rossiter, M. J., \& Derwing, T. M. (2012). Still far to go: Systematic programming for immigrant and refugee children and youth. In F. E. McCarthy \& M. H. Vickers (Eds.), Refugee and immigrant students: Achieving equity in education (pp. 89-106). Charlotte, NC: Information Age Publishing.

Stanovich, K. E. (1980). Toward an interactive-compensatory model of individual differences in the development of reading fluency. Reading Research Quarterly, 16(1), 32-71. https://doi. org $/ 10.2307 / 747348$

Toohey, K., \& Derwing, T. M. (2008). Hidden losses: How demographics can encourage incorrect assumptions about ESL High School students. Alberta Journal of Educational Research, 54(2), 178-193. Retrieved from http://ajer.journalhosting.ucalgary.ca/index.php/ajer/article/ 
view/628/611United Nations High Commissioner for Refugees. (2016). Education. Retrieved from http://www.unhcr.org/education.html

Vaughn, S., Klingner, J. K., Swanson, E. A., Boardman, A. G., Roberts, G., Mohammed, S.

S., \& Stillman-Spisak, S. J. (2011). Efficacy of collaborative strategic reading with middle school students. American Educational Research Journal, 48(4), 938-964. https://doi. org/10.3102/0002831211410305

Vygotsky, L. S. (1986). Thought and language (rev. and expanded ed.). Cambridge, MA: MIT Press.

\section{Appendix \\ Collaborative Strategic Reading Script (Expository Text)}

(adapted from Klingner et al., 2012)

Before reading

Everyone: Read the title, subtitle, special words, and pictures.

Leader: "What do you know about this topic?" (ask everyone in the group)

Everyone: Answer the leader's question.

Begin reading the first section when everyone is ready.

During reading - Clunks

Everyone: Read and underline clunks - three is enough.

Leader: "Everyone, write down your clunks in your CSR learning log."

Everyone: Write down the clunks you underlined.

Clunk Expert: "Please share one of your clunks, (name somebody)."

Student shares a clunk.

Clunk Expert: "Who knows the meaning of this clunk?"

Clunk Expert: Guide the group to use the four clunk strategies to solve the clunk.

Repeat for the remaining clunks or until time is up.

\section{During reading - Get the Gist}

Leader: "If there are no more clunks, let's get the gist."

Gist Expert: "What or who is the most important in this section?"

Everyone: As a group, decide on an answer to the gist expert's question.

Gist Expert: "Everyone, write down what you think is the gist in your learning log."

Everyone: Write down a gist statement.

Gist Expert: "Who wants to share their gist?"

Everyone: Take turns sharing your gist. Work together to write a common gist.

You can change the gist statement in your CSR log to make it better.

Leader: Make sure everyone stays on track. Have the group read the next section when everyone is ready. Then go back to

After reading - Wrap up

Leader: "It's time for questions."

Question Expert: "Let's think of questions to check our understanding." 
Everyone: In your CSR logs, write down a right-there question, a think-and-search question, and an author-and-you question. Remember to also write down answers to your questions!

Question Expert: "Who wants to share their question first?"

Somebody shares a question.

Question Expert: "Who know the answer to that question?"

Everyone: Try to find an answer to the question. Go back to the reading for help. Tell the group your answer.

Question Expert: Continue asking the group to share their questions until all of the questions have been shared and answered.

Leader: Make sure everyone stays on track.

\section{After reading - Review}

Leader: "Let's review what we just read. In your CSR logs, write down one or two most important ideas from this passage."

Everyone: Write down your own summary.

Leader: Ask everyone to share their statements. After, help the group to decide on one or two common review statements that includes only the most important information. Prepare to present the review statements to the rest of the class.

Everyone: Hand in your CSR learning logs when you have finished. 